\title{
The Effect of Surface Polishing on the Flexural Strength of Anorthite-based Porcelainised Stoneware
}

\author{
H. Yildirim, Y. Azakli, M. Tarakci, A. Capoglu* \\ Gebze Institute of Technology, Department of Materials Science and Engineering, \\ Istanbul Cad. No 101, PO Box 141, 41400 Gebze, Kocaeli, Turkey
}

\begin{abstract}
The effect of surface polishing on the flexural strength of anorthite based porcelainised stoneware was studied. The flexural strength results obtained from both polished and unpolished samples were analysed by using Weibull statistical method. The state of surfaces and microstructures of polished and unpolished samples were also characterised by profilometry and scanning electron microscopy. Typical flexural strength value obtained from anorthite based stoneware body fired at $1210{ }^{\circ} \mathrm{C}$ was about $100 \mathrm{MPa}$. The average flexural strength $\left(\sigma_{m}\right)$ and Weibull modulus $(m)$ values for as fired, ground, and ground and polished specimens increased sequentially with polishing degree. The surface roughness measurements and microstructure observations showed that the severity of the surface flaws declined as the polishing process proceeded. The obtainment of better strength behaviour with polishing was attributed to high crystalline to glassy phase ratio of the anorthite based porcelainised stoneware together with the formation of network structure of these anorthite crystals.
\end{abstract}

DOI: 10.12693 /APhysPolA.127.1336

PACS: 81.05.Je, 81.65.Ps, 62.20.mm

\section{Introduction}

The conventional porcelainised stoneware is highly densified material with a water absorption value of less than $0.5 \%$ by the formation of high quantity of glassy phase which forms an impervious surface layer covering more porous bulk structure therefore; the material does not require an additional glazing $[1,2]$. The conventional porcelainised stoneware bodies are generally produced from a green pressed body which is composed of 40-50 wt.\% kaolinitic clay, 35-45 wt.\% alkaline feldspars and $10-15$ wt. $\%$ quartz sand by fast firing in the $1200-1230^{\circ} \mathrm{C}$ temperature range [1]. Firing of the appropriate formulation of these materials produces a microstructure with 55-65 wt.\% amorphous phase and 20-25 wt.\% quartz, 12-16 wt.\% mullite crystalline phases $[1,3,4]$. Porcelainised stoneware materials are characterized by their high technical performances such as moderately high flexural strength and chemical, frost, stain and wear resistance. The porcelainised stoneware materials have been widely used both in door and outdoor applications as wall and floor covering tiles in construction industry because of its outstanding properties $[5,6]$. Especially the floor applications, where dynamic interaction exists between working surface of the tile and the surrounding environment, require long term reliability on the properties of material such as stain and wear resistance [7]. On top of these properties, the construction applications also require high aesthetical appearances, which can be improved by very expensive surface polishing process [8]. The industrial polishing procedure, which opens up the

* corresponding author; e-mail: capoglu@penta.gyte.edu.tr closed porosities and forms surface flaws and cracks by removing a surface layer of 0.4 to $0.8 \mathrm{~mm}$ in thickness, causes degradations on the stain resistance and mechanical properties of the polished tiles $[7,9]$. The degree of degradation on the performances or properties depends largely on the nature, types of the existing defects and microstructural homogeneity of the stoneware. The stain resistance of polished tiles strongly depends on tile microstructure, especially the morphology of pores present in the sintered tile body and surface defects such as grooves, scratches and cutting edges created by polishing process $[7,10]$.

A study carried out on polishing conventional porcelainised stoneware tiles, which were obtained from five different manufacturers showed that the flexural strength of polished tiles was lower than the unpolished tiles [11]. Also the reliability in strength values decreased in polished tiles as was shown by the Weibull statistical study. The decline in the reliability on the flexural strength values of polished tiles was related to the lack of homogeneity in microstructure and conditions of polishing process [11]. In another study, the influence of sintered porcelain tile microstructure on mechanical and surface properties were studied in detail [10]. The stoneware tiles having different microstructure were produced by varying the sintering temperature of porcelainised stoneware tiles that were produced from different bodies in which content and the particle size of quartz were varied. It was concluded that the surface and mechanical properties of polished porcelain tile depend strongly on tile microstructure, which is resulted from the starting composition and processing conditions.

Recently, a new porcelainised stoneware body was developed as an alternative material to the conventional porcelainised stoneware tiles [12]. This ma- 
terial was formulated to generate basically anorthite $\left(\mathrm{CaO} \cdot \mathrm{Al}_{2} \mathrm{O}_{3} \cdot 2 \mathrm{SiO}_{2}\right)$ crystals in the microstructure and to have a high crystalline to glassy phase ratio, after processing at $1200-1225{ }^{\circ} \mathrm{C}$ temperature ranges. Typical flexural strength value of this anorthite-based body is about $110 \mathrm{MPa}$ which is about three times higher than the strength value required by the international standards.

Although, this anorthite based body has not been commercialised yet, it is important to know the effect of surface polishing on the flexural strength behaviour of this anorthite based porcelainised stoneware material before the industrial scale production.

The aim of this study was to evaluate the effect of surface polishing on the flexural strength behaviour of anorthite based porcelainised stoneware body. The evaluation was realised by analysing the flexural strength data obtained from both polished and unpolished samples by the application of Weibull statistical method. The surface condition and microstructure of the materials were also characterised by profilometry and scanning electron microscopy (SEM) techniques.

\section{Experimental}

The effect of surface polishing on the flexural strength behaviour of anorthite based porcelainised stoneware was investigated by simulating, at a laboratory scale, the production and the polishing process.

In production of anorthite based stoneware body, FW 325 grade wollastonite, HTM-30 grade alumina, SS-600 grade quartz, Ukrainian ball clay and $\mathrm{MgCO}_{3}$ were used as raw materials. The chemical analyses of the raw materials and production details of anorthite based stoneware body are given in elsewhere [12]. In order to prepare $2 \mathrm{~kg}$ of batch, appropriate amounts of starting materials were weighed and wet mixed/milled for $48 \mathrm{~h}$ in a 51 porcelain pot containing 100 alumina balls with diameter of $\sim 15 \mathrm{~mm}$. After mixing/milling, the slurry was transferred to a plastic container and oven dried at $\sim 110{ }^{\circ} \mathrm{C}$. Dried cakes were broken up to form a powder, which was then granulated by first spraying with a fine mist of water droplets and then by agitating the damp powder. Test specimens having the dimensions of $7 \mathrm{~mm} \times 75 \mathrm{~mm} \times \sim 4 \mathrm{~mm}$ were shaped by means of a handoperated hydraulic press at $30 \mathrm{MPa}$.

The effect of surface polishing on the flexural strength was assessed by Weibull statistical analysis. However, prior to polishing study, the densification and flexural strength studies were carried out to determine the suitable temperature for fabricating well densified samples with high flexural strength value. For this purpose the samples were sintered at temperatures from $1150{ }^{\circ} \mathrm{C}$ to $1230{ }^{\circ} \mathrm{C}$ with soaking time of $3 \mathrm{~h}$, in the Nabertherm chamber kiln. The rate of heating was kept at $3{ }^{\circ} \mathrm{C} / \mathrm{min}$ and on completion of the soaking period, power to the furnace was automatically shut off and cooling rate was then dictated by the cooling rate of the furnace. Once the sintering temperature was established to produce specimens a different batch of 100 rectangular bars were shaped and sintered at the determined temperature in two separate runs under the same conditions.

Following the sintering, the fired specimens were made a single batch, which was then divided into three groups by picking up the samples randomly. The first group samples did not receive any polishing treatment and called "as fired". The second group of samples was wet ground sequentially using 80,120 and 180 grit $\mathrm{SiC}$ abrasive papers to simulate the calibrating stage in industrial polishing line and denoted as "calibrated". The third group of samples was firstly wet ground by using $80-2400$ grit $\mathrm{SiC}$ abrasive papers and then polished by using 6 and $3 \mu \mathrm{m}$ diamond paste and called as "calibrated and polished".

The flexural strength of the prepared samples was measured by using a universal tester (Model 5569, Instron ltd.) by a three point bending fixture with a lower span of $50 \mathrm{~mm}$ and crosshead speed of $1 \mathrm{~mm} / \mathrm{min}$, based on ASTM standard C1161-90.

The flexural strength data for each group of "as fired", "calibrated", and "calibrated and polished", 33 nominally identical specimens with specific flaw distributions were ranked in ascending order and a Weibull statistical analysis was carried out on the resultant data using Eq. 1:

$$
P_{n}=1-\exp \left[-\left(\frac{\sigma_{r}-\sigma_{u}}{\sigma_{0}}\right)^{m}\right],
$$

where, $P_{n}$ is the probability of failure, $\sigma_{r}$ is the fracture stress, $\sigma_{u}$ is the threshold stress below which the probability of failure is zero, $\sigma_{0}$ is a normalising parameter, often selected as the characteristic stress at which the probability of failure is 0.632 and $m$ is the Weibull modulus which describes the narrowness of the distribution. Assuming $\sigma_{u}=0$, and adopting as probability estimator of failure $P_{n}=(i-0.5) / N$, where $N$ is the number of the measurements and $i$ is the ranking number, with $i=1$ for the weakest specimen and $i=N$ for the strongest, the Weibull modulus $m$ and the parameter $\sigma_{0}$, were determined by rearranging the Eq. 1 as:

$$
\ln \ln \left(\frac{1}{1-P_{n}}\right)=m \ln \left(\sigma_{r}-\sigma_{u}\right)-m \ln \sigma_{0} .
$$

The surfaces of the samples which were representing of "as fired", "calibrated", "calibrated and polished" groups were examined by a Phillips XL30 SFEG scanning electron microscope (operating at $20 \mathrm{kV}$ ). Before SEM examination the surfaces of samples were coated by gold. A stylus profilometer (Dektak 8, Veeco) was also employed to examine the topography of the surfaces and measure the surface roughness values. An area of $1 \mathrm{~mm} \times 1 \mathrm{~mm}$ on the surface of the samples was scanned by applying $5 \mathrm{mg}$ stylus force. The resolutions in $\mathrm{X}$ - and $\mathrm{Y}$-axis were 0.111 and $3.175 \mu \mathrm{m} / \mathrm{sample}$, respectively. The surface roughness ( $\mathrm{Ra}$ ) described as the arithmetic average deviation from the mean line within the assessment length and the sum of the maximum valley and maximum peak of the roughness within the assessment length (Rt) values were calculated by using the dedicated software (Vision 3.5) [13]. 
For XRD, powdered form of sintered samples were scanned from $2 \theta=10$ to $70^{\circ}$, at a scanning speed of $1^{\circ} /$ min, using a RIGAKU 2200 DMAX diffractometer (with $\mathrm{CuK}_{\alpha}$-radiation, $\lambda=0.154 \mathrm{~nm}$ ) at $40 \mathrm{kV}$ and $40 \mathrm{~mA}$. Before SEM examination the crystalline phases were revealed by etching the samples in a $5 \% \mathrm{HF}$ solution to remove the glass phase.

\section{Results}

The anorthite based porcelainised stoneware body was processed and its densification and flexural strength behavior against the sintering temperature was characterized. Figure 1 shows both bulk density and flexural strength behavior of the body sintered in the temperature range from 1150 to $1230{ }^{\circ} \mathrm{C}$. As the sintering temperature increases, bulk density of the body continued to increase and it reached its maximum at $1180{ }^{\circ} \mathrm{C}$, upon further heating bulk density started to decrease slightly producing quite a large firing range. The variation in flexural strength values of the sintered anorthite based material showed similar trend to its densification behavior as seen in Fig. 1. The flexural strength values were in between 100 and $120 \mathrm{MPa}$ for the materials sintered in temperature range from 1170 to $1230{ }^{\circ} \mathrm{C}$. As the preliminary study showed that the flexural strength values were not changing immensely with sintering temperature, it was decided to sinter all samples at $1210^{\circ} \mathrm{C}$ to obtain maximum degree of crystallinity for the Weibull study.

Typical XRD pattern obtained from a sample sintered at $1210{ }^{\circ} \mathrm{C}$ is shown in Fig. 2. The crystalline phases identified are anorthite being the major phase and cristobalite and corundum being the minor phases. SEM image taken from the chemically etched surface of the sample sintered at $1210{ }^{\circ} \mathrm{C}$ is given in Fig. 3. This image clearly indicates high degree of crystallinity and the distribution of different types of crystals developed in the microstructure. A series of SEM-EDS analysis obtained from different regions of the same sample is also given in Fig. 3. These results indicate the formation of anorthite crystals (Fig. 3a), marked as "a", corundum crystals (Fig. 3c), marked as "c", and cristobalite crystals (Fig. 3q), marked as "q" and glassy phase, marked as "g", which is etched away to reveal the crystalline phases. Tabular shaped unreacted alumina grains $\sim 10 \mu \mathrm{m}$ in length and unreacted residue of quartz grains, which were transformed to cristobalite during cooling, were distributed evenly among the network of anorthite crystals.

The Weibull plot indicating the average flexural strength $\left(\sigma_{0}\right)$, Weibull modulus $(\mathrm{m})$ values obtained from three groups of samples each of which were treated to have different surface conditions is given in Fig. 4 . The average flexural strength values of samples, namely "as fired", "calibrated", and "calibrated and polished" were 100, 115 and $122 \mathrm{MPa}$, respectively. Similarly, the Weibull modulus values were slightly increasing with polishing treatments. It should be noted that the scatterings in flexural strength values within each group of samples were quite low. The SEM micrographs showing the surface quality of "as fired", "calibrated", and "calibrated and

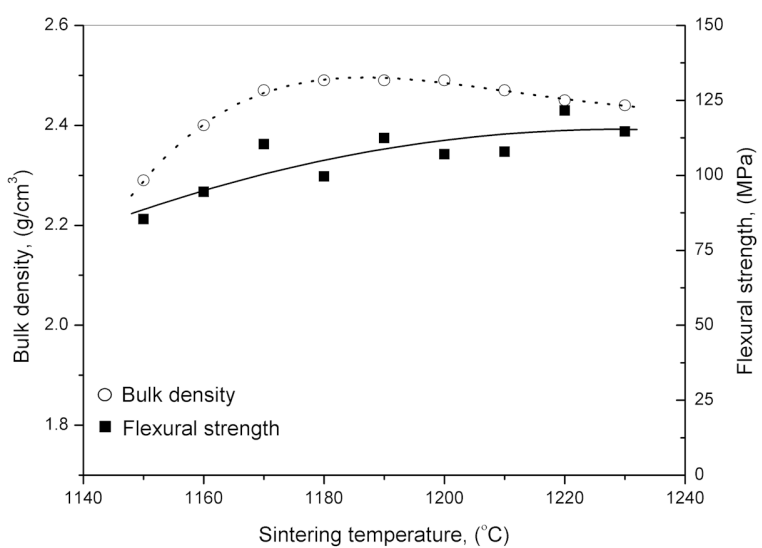

Fig. 1. Variation in density and flexural strength of anorthite based stoneware body with sintering temperature.

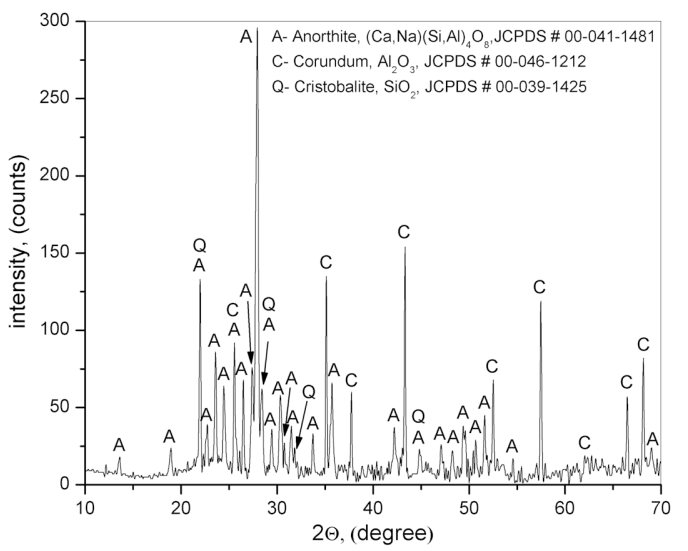

Fig. 2. An XRD pattern obtained from a sample sintered at $1210{ }^{\circ} \mathrm{C}$ for $3 \mathrm{~h}$.

polished" samples were are given in Fig. 5a-f. Figures 5a and $b$ show the SEM images obtained from the surface of "as fired" sample. The surface of sample is very rough containing small bubbles some of which even were burst (Fig. 5b). Figure 5c and d show the effect of calibrating (grinding) treatment on the surface of the sample. Parallel scratch lines due to coarse grinding are clearly visible on the surface (Fig. 5c). The severity of scratches became more apparent at higher magnification (Fig. 5d). The SEM image shows clearly the loosely bound chips at the edges of the scratches and flaws within the groove. Sphere shaped closed porosities also become apparent once the surface layer was removed. However, the diameters of these porosities were relatively smaller than the width of the groove produced by coarse grinding. These deep scratch marks were removed almost completely after grinding and polishing treatment and the typical view of the surface of sample is given in Fig. 5e. The figure depicts the morphology of pores which were isolated, rounded and evenly distributed with different sizes. The diameter of the largest pore is about $20 \mu \mathrm{m}$ as can be seen in Fig. $5 f$. 

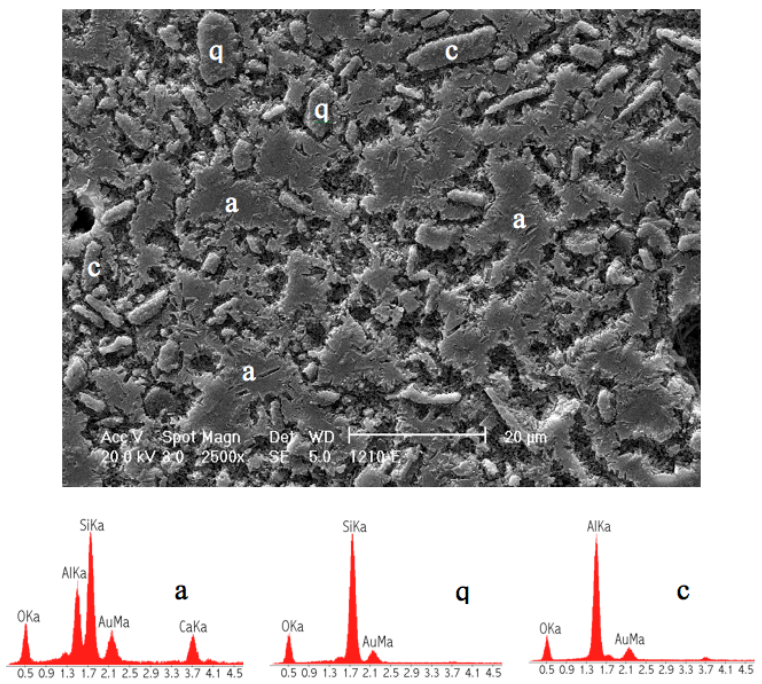

Fig. 3. The microstructure and EDS spectrum of anorthite based stoneware sintered at $1210{ }^{\circ} \mathrm{C}$ for $3 \mathrm{~h}$ showing a) anorthite, q) cristobalite c) corundum, and glass formation labelled as a, c, q, and g, respectively.

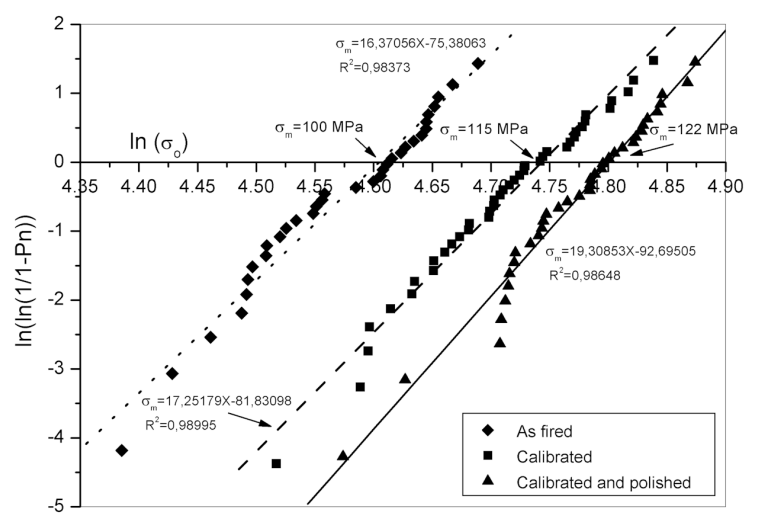

Fig. 4. Weibull plots of "as fired", "calibrated", and "calibrated and polished" samples.

Topographic maps (3-D) of the "as fired", "calibrated", and "calibrated and polished" samples are given in Fig. 6a-c. As fired sample (Fig. 6a) has a very rough surface containing both hills and valleys created by the burst and unexploded bubbles. Typical maximum valley and maximum peak of the roughness $(\mathrm{Rt})$ value is about $37 \mu \mathrm{m}$ and surface roughness ( $\mathrm{Ra}$ ) value is $4.08 \mu \mathrm{m}$. The grinding reduced the surface roughness value $(\mathrm{Ra})$ from $4.08 \mu \mathrm{m}$ to $1.20 \mu \mathrm{m}$ however; it did not affect the Rt value at all. Further polishing (calibration and polish) treatment reduced both the $\mathrm{Ra}$ and $\mathrm{Rt}$ values down to $0.50 \mu \mathrm{m}$ and $31.41 \mu \mathrm{m}$, respectively.

\section{Discussion}

The Weibull statistical analysis of anorthite based porcelainised stoneware showed that both average flexural strength and Weibull modulus values increased con- siderably with the polishing processes. However, according to a study carried out on the conventional porcelainised stoneware materials from five different manufacturers, both average flexural strength and Weibull modulus were found to decrease significantly with polishing treatment [11]. It was postulated that the decrease in strength with polishing was due to the difference in microstructural texture, and surface damages induced by the grinding and polishing processes.

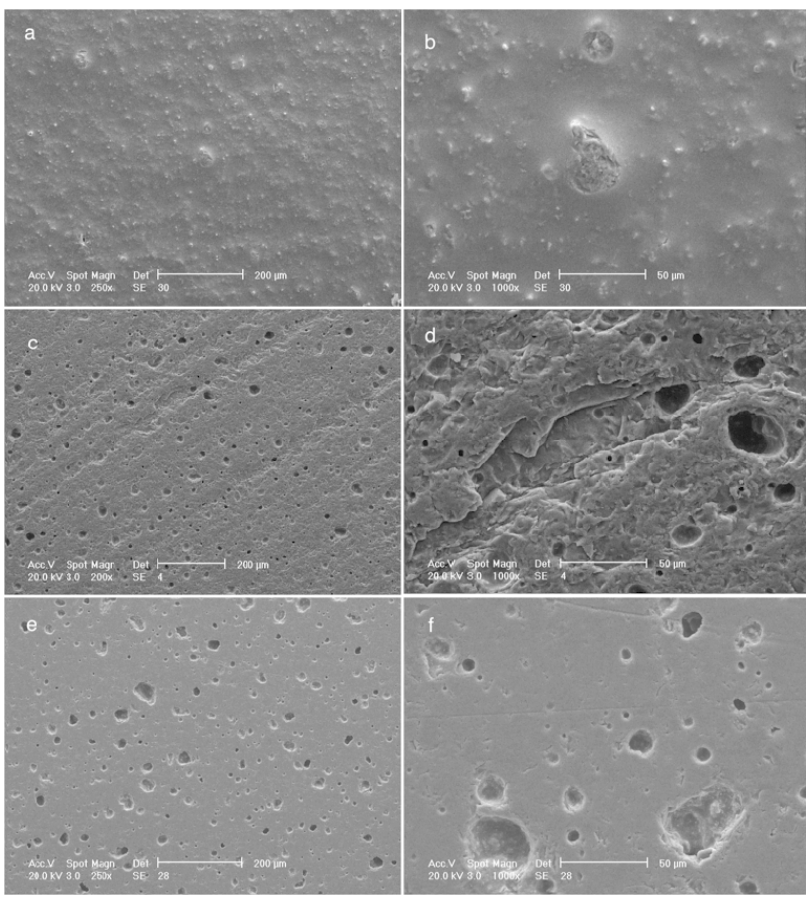

Fig. 5. SEM images of the surfaces of samples at two different magnifications; (a, b) "as fired", (c, d) "calibrated", and (d, e) "calibrated and polished".

The contradiction between the flexural strength performance of polished and unpolished samples of conventional and anorthite based porcelainised stonewares could be explained by the difference in the crystallinity degree of these two types of stonewares. The conventional porcelainised stoneware contains high amount of glassy phase which varies between 59 and $67 \%$ and crystalline phases, namely mullite $(8-17 \%)$ and un-reacted residue of quartz grains (17-28\%) [1]. On the other hand, the anorthite based porcelainised stoneware contains $\sim 52$ wt.\% anorthite, $\sim 12$ wt. $\%$ corundum and $\sim 8$ wt. $\%$ cristobalite and glassy phase ( 28 wt.\%) [12].

An improvement in the mechanical behaviour of stoneware ceramics can be achieved by increasing the crystalline to glassy phase ratio [14]. Besides an increase in crystallinity, crack deflection, i.e. propagation of crack front around grains and second phase formation is the main mechanism that contributes to an increase in fracture toughness [15]. Therefore, an increase in crystal size and second phase formation are desirable. It was reported by several authors that alumina [16], cristo- 


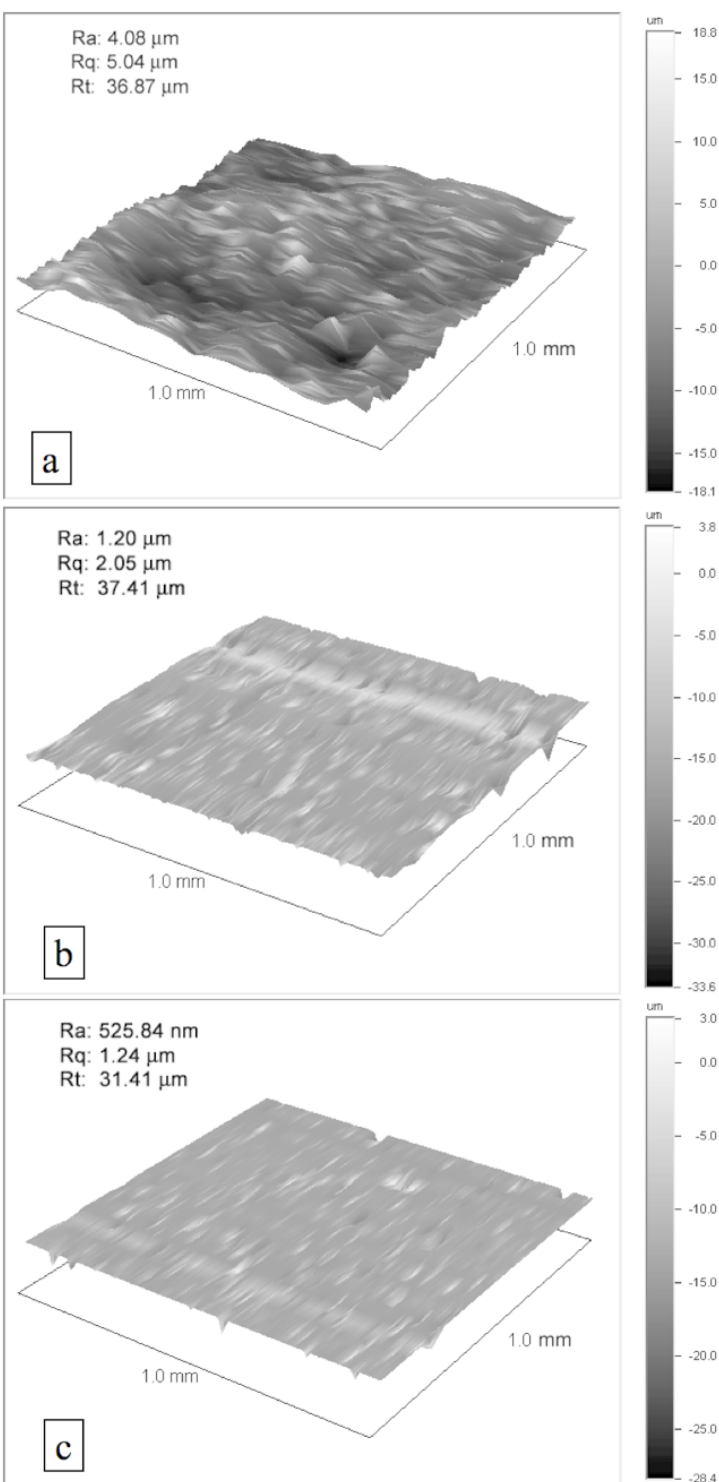

Fig. 6. 3-D Topographic images of the surface of samples; (a) "as fired", (b) "calibrated", (c) "calibrated and polished".

balite [17], silica fume [18], rice husk ash [19, 20] and mullite [21] in traditional ceramics each strengthen the fired body.

Since the anorthite based porcelainised stoneware develops additional crystalline phases (Fig. 2), namely corundum and cristobalite on top of high degree of crystallinity of anorthite crystals which were forming a network in the microstructure (Fig. 3), it is prone to resist the propagation of cracks that may be created on the surface of sample during grinding and polishing process.

The average flexural strength and Weibull modulus (Fig. 4) of anorthite based body increases also with the individual grinding, and grinding and polishing processes. The strength is a function of the characteristic defect (e.g., porosity, surface flaw) size of the material. The increase in strength may be explained by a decrease in defect size. As can be seen in Fig. 5d the size of the defects that were created during grinding is much higher than the size of porosities. However, most of these grinding defects were removed from the surface during the fine polishing (Fig. 5f). The elimination of these grinding defects would help increasing the strength by leaving behind only the porosities as a defect for the reduction of strength. Also, obtaining homogeneously distributed small sized, rounded shape and isolated pores in the microstructure after sintering of the anorthite based porcelainised stoneware is beneficial for achieving high flexural strength values.

The difference in the average flexural strength values of polished and unpolished anorthite based porcelainised stoneware samples could be explained by the surface roughness $(\mathrm{Ra})$. As the topographic maps in Fig. 6 indicate that the surface of un- polished sample is very rough compare to surfaces of treated samples. This unevenness on the topography of surface of unpolished sample would lead to inhomogeneous contacting during loading in the flexural strength testing. This would then cause the stress to concentrate in rather smaller contacting areas than the actual areas which were supposedly being stressed during testing. It should also be mentioned that the surface flaws created by the bursting of gas bubbles which were formed during sintering and reached at the surface of the sample would contribute in the reduction of flexural strength value of as fired samples.

Even though the sum of the maximum valley and maximum peak of the roughness Rt value of "as fired" sample was higher than that of "calibrated and polished" sample the stain resistance of the "as fired" sample would expected to be better than the stain resistance of "calibrated and polished" sample. Since no material was removed from the surface of "as fired" sample all the pores are closed porosities however, when the outer surface was removed by the polishing process then the closed porosities become open porosities which are significantly deeper as the Rt value of polished sample indicate.

\section{Conclusions}

The flexural strength behaviour of the polished and unpolished samples of anorthite based porcelainised stoneware body was evaluated by Weibull statistical analysis and it was found that both average flexural strength and the Weibull modulus values were gradually increasing with progress of polishing processes.

It was observed that the surface defects already present on the "as fired" samples and the defects created on the surface during coarse grinding are more detrimental than the existing porosities in microstructure for reduction in flexural strength. Accordingly, the defects created on the surface during coarse grinding are also more effective than existing porosities in the microstructure for the reduction of flexural strength.

For obtaining high flexural strength, the homogeneity of shape, size and distribution of porosities in the microstructure obtained in anorthite based porcelainised 
stoneware after sintering is very critical. Ultimately, the high crystalline to glassy phase ratio of the anorthite based porcelainised stoneware together with the formation of network structure of these anorthite crystals are thought to be very effective for obtaining relatively high strength even after grinding and polishing treatments.

\section{References}

[1] G.E.M. Dondi, C. Melandri, C. Mingazzini, M. Marsigli, Interceramic 48, 75 (1999).

[2] C. Leonelli, F. Bondioli, P. Veronesi, M. Romagnoli, T. Manfredini, G.C. Pellacani, V. Cannillo, J. Eur. Ceram. Soc. 21, 785 (2001).

[3] S. Kumar, K.K. Singh, P. Ramachandrarao, J. Mater. Sci. 36, 5917 (2001).

[4] A. Tucci, L. Esposito, L. Malmusi, E. Rambaldi, J. Eur. Ceram. Soc. 27, 1875 (2007).

[5] T. Manfredini, G.C. Pellacani, M. Romagnoli, L. Pennisi, Am. Ceram. Soc. Bull. 74, 76 (1995).

[6] P. Burzacchini, Ceram. World Rev. 10, 96 (2000).

[7] G.E.M. Dondi, G. Guarini, C. Melandri, M. Raimondo, E.R.E. Almendra, P.M.T. Cavalcante, J. Eur. Ceram. Soc. 25, 357 (2005).

[8] L.E.E. Rambaldi, A. Tucci, G. Timellini, J. Eur. Ceram. Soc. 27, 3509 (2007).

[9] L. Esposito, A. Tucci, Am. Ceram. Soc. Bull. 79, 59 (2000).
[10] E. Sanchez, M.J. Ibanez, J. Garcia-Ten, M.F. Quereda, I.M. Hutchings, Y.M. Xu, J. Eur. Ceram. Soc. 26, 2533 (2006).

[11] L. Esposito, A. Tucci, D. Naldi, J. Eur. Ceram. Soc. 25, 1487 (2005).

[12] M.U. Taskiran, N. Demirkol, A. Capoglu, J. Eur. Ceram. Soc. 25, 293 (2005).

[13] L.B.D. Page, C. Kowalski, J. Valencia, Dektak 8 advanced development profiler manual, USA:Veeco Instruments Inc., 2004.

[14] C.B. Ustundag, Y.K. Tur, A. Capoglu, J. Eur. Ceram. Soc. 26, 169 (2006).

[15] R.W. Rice, J. Mater. Sci. 32, 1673 (1997).

[16] N.S.R. Harada, H. Ishida, American Ceramic Society, 88 (1996).

[17] W.P. Tai, K. Kimura, K. Jinnai, J. Eur. Ceram. Soc. 22, 463 (2002).

[18] C.S. Prasad, K.N. Maiti, R. Venugopal, Ceram. Int. 28, 9 (2002).

[19] C.S. Prasad, K.N. Maiti, R. Venugopal, Ceram. Int. 27, 629 (2001).

[20] C.S. Prasad, K.N. Maiti, R. Venugopal, Ceram. Int. 29, 907 (2003).

[21] W.M. Carty, U. Senapati, J. Am. Ceram. So. 81, 3 (1998). 